\title{
Efeitos Naturais e Antrópicos nas Alterações dos Teores de Oxigênio Dissolvido: Uma Comparação Entre as Bacias do Rio Amazonas e Piracicaba
}

\author{
Catia Andersen Casagrande, José Mauro Sousa Moura, André Marcondes A. Toledo, Paula Munhoz Antunes \\ Ariovaldo Antônio Tadeu Lucas, Érica Pinazza, Michelle Cogo, Luiz Antonio Martinelli \\ Centro de Energia Nuclear na Agricultura (CENA) e Escola Superior de Agricultura "Luiz de Queiroz" (ESALQ) - USP \\ catiacasagrande@gmail.com,jmaurosm@gmail.com,amatoledo@gmail.com,pantunes@cena.usp.br \\ aatlucas@esalq.usp.br,epinazza@semaepiracicaba.org.br, mccogo@gmail.com,zebu@cena.usp.br
}

Recebido: 07/10/04 - revisado: 03/03/05 - aceito: 25/09/06

\section{RESUMO}

A compreensão do comportamento do Oxigênio Dissolvido (OD) em corpos d'água é fundamental para identificar os possíveis agentes causadores de desequilíbrio nesses ecossistemas. Em algumas regiões do Brasil expressivas variações na concentração do OD têm sido observadas nas águas de rios com diferentes graus de perturbação. Diante disto, este trabalho teve como objetivo analisar a situação do oxigênio dissolvido nas bacias hidrográficas dos rios Amazonas e Piracicaba, situados respectivamente nas regiões Norte e Sudeste do Brasil, a fim de identificar quais os agentes ou processos envolvidos nas variações dos teores do OD nesses sistemas. Na bacia do rio Piracicaba pôde-se observar que as baixas concentrações do OD nos cursos d'água estão relacionadas às fontes pontuais de poluição, decorrentes da ação antrópica, com elevado volume de efluentes sem prévio tratamento advindo dos grandes centros urbanos. A concentração do OD diminui consideravelmente ao longo do canal principal da bacia do rio Piracicaba, com valores médios que variam de $8,7 \mathrm{mg} \mathrm{L}^{-1}$, na região das nascentes, a 1,2 $\mathrm{mg} \mathrm{L}^{-1}$, após atravessar os maiores centros urbanos, indicando a influência dos efluentes domésticos e industriais na qualidade da água. Baixos valores de OD também foram observados nas águas do rio Amazonas, no entanto, essas variações são decorrentes de processos naturais, principalmente da oxidação da matéria orgânica e da sazonalidade do regime hídrico, determinando valores que variam de 4,0 a 5,4 $\mathrm{mg} \mathrm{L}^{-1}$ no periodo da cheia do rio Amazonas, que ocorre nos meses de junho e julho, e maiores valores no periodo de seca, em novembro, atingindo valores de aproximadamente 6,6 mg $L^{-1}$. Portanto, conclui-se que no Brasil a avaliação da qualidade da água deve considerar outros fatores que causam diminuição no teor de oxigênio dissolvido, já que a concentração deste elemento varia também em função de características físicas e climáticas regionais e não somente devido à interferência antrópica.

Palavras chaves: oxigênio dissolvido; rio Amazonas; rio Piracicaba; qualidade da água; esgoto.

\section{INTRODUÇ̃̃O}

O oxigênio dissolvido (OD) nos sistemas aquáticos é fundamental para as atividades e manutenção do metabolismo de organismos aeróbios. Ele representa $35 \%$ do total de gases presente na água e provém predominantemente da atmosfera e dos processos fotossintéticos de plantas aquáticas, principalmente das algas. A concentração de oxigênio dissolvido é influenciada pela atividade da biota presente nos corpos d'água, pela temperatura e pressão atmosférica entre outros fatores. Enquanto organismos fotossintetizantes produzem $\mathrm{O}_{2}$, os demais organismos o utilizam na respiração, sendo que esse balanço entre respiração e fotossíntese pode ser facilmente quebrado por pequenas alterações do ambiente (Wetzel, 1975).
A solubilidade e especialmente a dinâmica do oxigênio em rios e lagos, são aspectos de extrema importância para compreender a distribuição e desenvolvimento da biota aquática. Desse modo, o teor de oxigênio dissolvido pode ser considerado um dos indicadores da condição da água no que diz respeito ao seu estado de degradação.

No Brasil em geral, a grande maioria da carga de esgoto urbano é despejado sem prévio tratamento diretamente nos corpos hídricos (Daniel et al., 2002). Apesar do vigoroso desenvolvimento econômico dos municípios que compõe a bacia do Piracicaba (SP) são poucas as cidades que têm sistemas adequados de tratamento de esgoto doméstico (Martinelli et al., 2002). Em decorrência dessa prática os rios e ribeirões dessa região, e outras do Estado de São Paulo, vêm sofrendo constante degradação. 
Nessas regiões, com grande concentração urbana e lançamento de efluentes com alta carga orgânica nos corpos d'água, o oxigênio é um parâmetro extremamente utilizado como indicativo da poluição, sendo que a baixa qualidade da água tem sido relacionada, dentre outros fatores, com os baixos teores de oxigênio dissolvido (Krusche et al., 1997; Ballester et al., 1998; Ometto et al., 2000). Contudo, deve-se considerar que embora o oxigênio dissolvido seja um bom indicador, este não deve ser o único fator considerado, visto que, sua concentração é afetada por diversos fatores e não somente pela ação antrópica. Baixos teores de oxigênio dissolvido também podem ser encontrados em ecossistemas não degradados, como por exemplo, na bacia Amazônica (Forsberg et al., 1988; Devol et al., 1995; Richey et al., 1990).

Diante da necessidade de um gerenciamento adequado dos recursos hídricos, a fim de garantir o suprimento de água de qualidade para os diversos usos, os processos naturais ou antrópicos que interferem na qualidade da água e as fontes potenciais de poluição devem ser identificados e compreendidos.

Desse modo, este trabalho tem como objetivo investigar os teores de oxigênio dissolvido em duas bacias hidrográficas com características distintas, a fim de mostrar que alterações nos teores de OD podem ocorrer pela ação antrópica ou através de processos naturais.

\section{MATERIAL E MÉTODOS}

\section{Áreas de estudo}

As áreas de estudo são a bacia do rio Piracicaba, a qual estende-se por aproximadamente $12.400 \mathrm{~km}^{2}$ e localiza-se no Estado de São Paulo, e a bacia Amazônica com aproximadamente 6.925.674 $\mathrm{km}^{2}$, a qual situa-se na região Norte do Brasil. Na Figura 1 observa-se a bacia do rio Piracicaba, o qual é formado pela junção de três rios, Jaguari, Atibaia e Camanducaia (Ballester et al., 1998), bem como os pontos de amostragem. A bacia está localizada em uma região desenvolvida do Estado de São Paulo. As características dessa bacia vêm mudando com o passar do tempo, uma vez que, nas últimas décadas, a região sofreu um processo de industrialização e aumento na população, principalmente a urbana. A densidade demográfica da bacia do Piracicaba é de aproximadamente 238 habitantes $\mathrm{km}^{-2}$ e a atividade industrial é bem diversificada, destacando-se a indústria petroquímica na região de Paulínia e indústrias sucro-alcooleiras nas áreas de cultivo de canade-açúcar. $\mathrm{Na}$ agricultura há predominância de pastagens e cultura da cana-de-açúcar (CBH-PCJ, 2000).

A Figura 2 apresenta o rio Amazonas com os seus tributários destacando-se os pontos de coleta. Os principais tributários do rio Solimões/Amazonas são: rio Içá, Jutaí, Juruá, Japurá, Purus, Negro e Madeira.

A densidade demográfica na bacia Amazônica é de aproximadamente 1,1 habitantes $\mathrm{km}^{-2}$ (ANA, 2002), a floresta tropical é a principal cobertura do solo, o clima é do tipo tropical chuvoso, quente e úmido. A bacia na porção oeste drena solos pouco intemperizados da região Andina e Subandina, nas regiões Norte e Sul os tributários drenam os escudos cristalinos Norte e Sul, respectivamente. A disposição dos tributários em relação aos escudos tem grande influência na composição química da água e dos elementos em suspensão nela presentes. A ocupação da região Amazônica dá-se principalmente através da formação de pequenas comunidades afastadas dos centros urbanos, com algumas exceções como, por exemplo, Manaus que tem mais de um milhão de habitantes. Este modelo não acarreta grande pressão antrópica aos corpos d'água devido ao não lançamento de efluentes, com exceção dos grandes centros urbanos da região, como Manaus, Belém, Porto Velho e Rio Branco, onde a prática de despejo in natura de esgoto doméstico vem causando uma deterioração acentuada nos corpos hídricos.

\section{Análise dos dados}

A distribuição dos teores de oxigênio dissolvido nas águas dos rios das duas regiões foi investigada através de dados obtidos pelos projetos científicos CAMREX (Carbon in the AMazon River EXperiment) (Richey et al., 1986), na bacia Amazônica, e PiraCena, na bacia do rio Piracicaba (SP) (Martinelli et al., 1999).

Dentre os parâmetros fornecidos pelas fontes foram avaliados o teor de oxigênio dissolvido e a vazão dos rios e procurou-se realizar uma análise das variações sazonais desse parâmetro. As coletas do CAMREX foram realizadas em diferentes épocas do ano entre o período de 1982 a 1991 e do Projeto PiraCena entre o período de 1995 a 1999. 


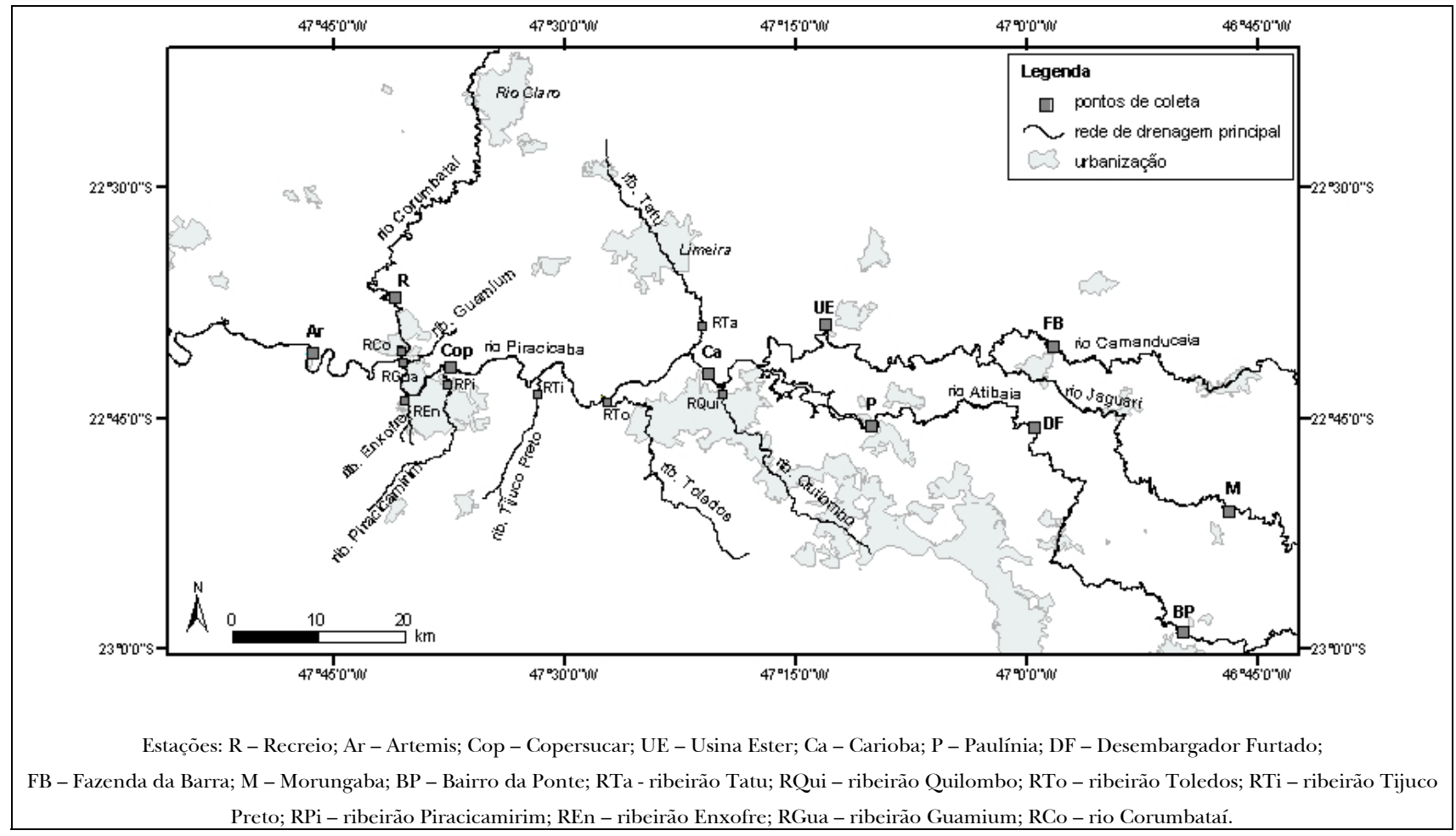

Figura 1 - Principais rios e ribeirões que compõem a bacia do rio Piracicaba e localização dos pontos de coleta.

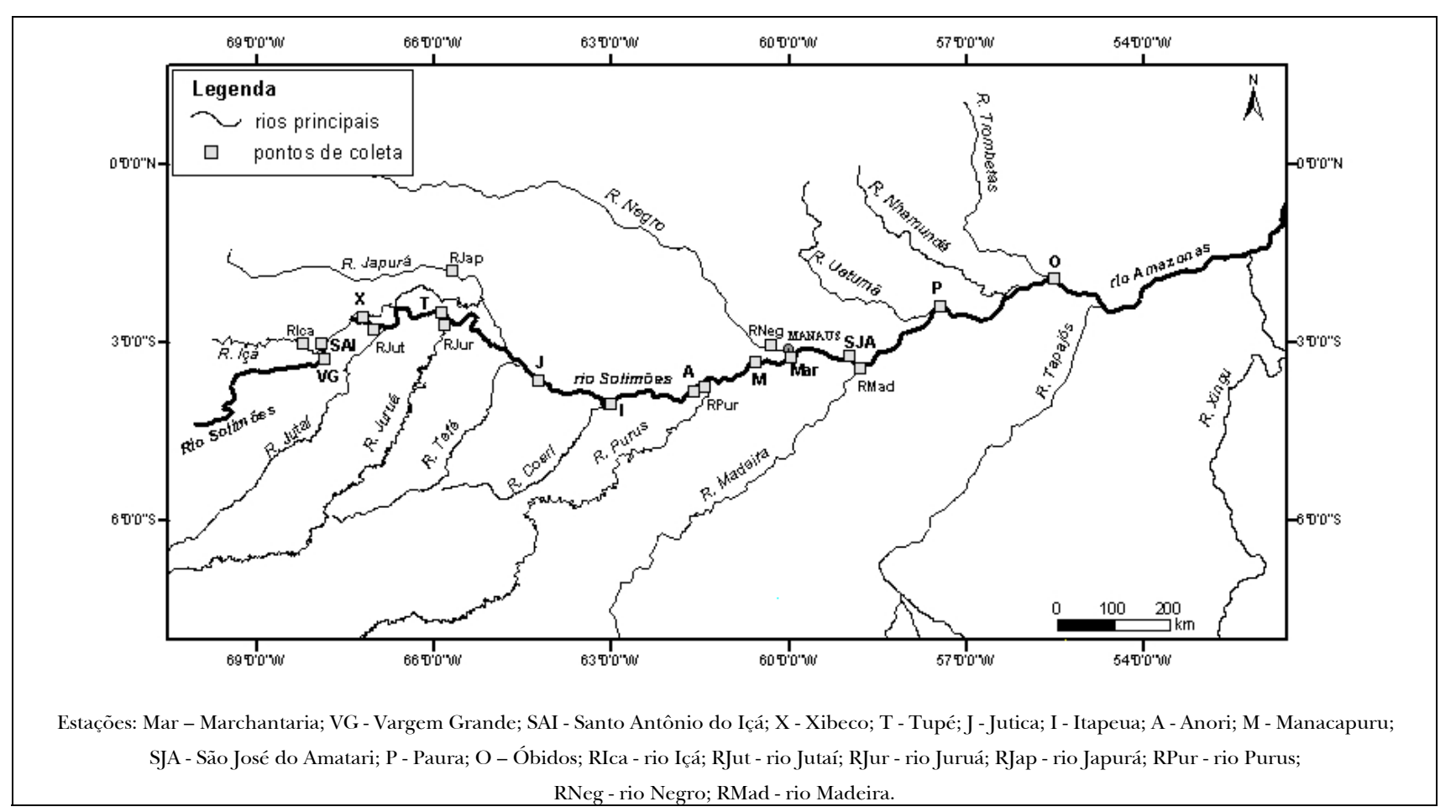

Figura 2 - Rio Solimões/Amazonas com seus tributários e localização dos pontos de coleta. 
A concentração do oxigênio dissolvido encontra-se expressa em $\mathrm{mg} \mathrm{L}^{-1}$. A temperatura média anual da água nas regiões de coleta é de $27{ }^{\circ} \mathrm{C}$ na bacia Amazônica e de $21{ }^{\circ} \mathrm{C}$ para a bacia do Piracicaba. Cabe ressaltar que a temperatura afeta a solubilidade do oxigênio e que o convencional seria expressar os valores em porcentagem de saturação considerando a temperatura do dia da coleta. No entanto, devido à ausência dos valores de temperatura para todos os dias das coletas e considerando que a diferença deste parâmetro nas duas bacias é em média $6{ }^{\circ} \mathrm{C}$, optou-se por manter os valores originais, visto que isto não afeta significativamente a comparação realizada.

As determinações das concentrações de oxigênio dissolvido dos rios da bacia do Piracicaba foram realizadas nos seguintes locais: Bairro da Ponte, Desembargador Furtado e Paulínia no rio Atibaia; Morungaba e Usina Ester no rio Jaguari; Fazenda da Barra no rio Camanducaia; Carioba, Copersucar e Artemis no rio Piracicaba e Recreio no rio Corumbataí (Figura 1). As medições foram realizadas mensalmente durante os anos de 1995, 1996 e 1997.

Na região central da bacia do rio Piracicaba realizou-se análise mais detalhada considerando os principais ribeirões que recebem grande volume de efluentes dos maiores centros urbanos da bacia, conforme Figura 1. Os ribeirões analisados foram: ribeirão Tatu que drena o município de Limeira, ribeirão Quilombo responsável pela drenagem do município de Americana, ribeirão Toledos que atravessa o município de Santa Bárbara d'Oeste, ribeirão Tijuco-Preto que drena uma área agrícola e o distrito de Tupi, ribeirão Piracicamirim responsável pela drenagem de $1 / 3$ da cidade de Piracicaba, ribeirão Enxofre drenando parte do município de Piracicaba, ribeirão Guamium e por fim, rio Corumbataí. As medições de OD nesses ribeirões foram feitas nos anos de 1998 e 1999 em períodos de cheia e de estiagem. De todos os pequenos tributários analisados apenas o ribeirão Piracicamirim tem um sistema de tratamento de esgoto, o qual foi construído no ano de 1998. Os demais despejam toda a carga de esgoto proveniente dos municípios no rio Piracicaba.

Na bacia Amazônica foram determinados 19 pontos de coleta ao longo do rio Solimões e seus tributários, sendo um local amostrado com maior número de repetições (Marchantaria) (Devol et al.,1995), o qual possibilitou uma análise mais detalhada das variações sazonais dos parâmetros considerados (Figura 2).

As variações sazonais, cheia e seca, entre as duas bacias analisadas são distintas. O período con- siderado de cheia no rio Piracicaba se dá em janeiro e fevereiro (ESALQ 2003), enquanto no rio Amazonas a maior vazão ocorre nos meses de junho e julho. O período de maior vazão do rio Piracicaba é também o período de maior precipitação na região. Já na bacia do rio Amazonas existe uma defasagem entre o período de maior precipitação (março e abril) e período de maior vazão do rio (Telles, 2002; Moura, 2005). Este efeito é determinado predominantemente, pelo tempo de residência da água no solo, nas áreas inundáveis (várzeas e igapós) e nos canais, cujas magnitudes estão relacionadas às grandes dimensões das bacias de drenagem que contribuem para o escoamento dos principais rios dessa região.

Para analisar a influência do esgoto nos corpos d'água de ambas bacias, foram efetuados cálculos relacionando esgoto gerado e disponibilidade de água. A estimativa do volume de esgoto gerado segue a equação:

$\mathrm{Eg}=\mathrm{P} * \mathrm{f}_{1}$

onde:

Eg é o volume de esgoto gerado $\left(\mathrm{m}^{3} \mathrm{dia}^{-1}\right)$;

$\mathrm{P}$ é a população atendida pela rede de esgoto, de acordo com ANA (2002) e CBH-PCJ (2000);

f1 é a produção média diária de esgoto por habitante $\left(0,180 \mathrm{~m}^{3} \mathrm{dia}^{-1}\right)$, segundo Martinelli et al. (2002).

Segundo ANA (2002) e CBH-PCJ (2000), na bacia do rio Piracicaba e do rio Amazonas, $80 \%$ e $10,4 \%$ da população, respectivamente, é servida por coleta de esgoto e $17 \%$ e $2,3 \%$ do esgoto gerado passa por algum processo de tratamento.

Adicionalmente, foi estimada a relação $(\mathrm{R})$ entre a disponibilidade de água e o volume de esgoto de ambas bacias, conforme a seguinte equação:

$$
\mathrm{R}=\frac{\mathrm{D}}{\mathrm{Eg} *}
$$

onde:

$D$ é a disponibilidade de água $\left(\mathrm{m}^{3} \mathrm{dia}^{-1}\right)$, de acordo com ANA (2002) e CBH-PCJ (2000);

Eg* é o volume de esgoto gerado menos o percentual de esgoto tratado.

Para a bacia Amazônica, um balanço de massa ao longo do canal principal foi realizado em diferentes períodos para se avaliar o comportamento conservativo ou não dos teores de OD. Cabe res- 
saltar que o referido balanço não engloba todas as entradas de água no sistema, dada a falta de dados de vazão dos pequenos tributários que drenam água para o rio principal. Este fator pode ser responsável por maiores diferenças no balanço no período da descida das águas. Assim, para minimizar os erros, a vazão de saída foi considerada a mesma da entrada, ou seja, a soma das vazões das demais estações consideradas no balanço.

O balanço foi realizado segundo a equação 3, considerando as estações Vargem Grande e Óbidos, no rio Solimões/Amazonas, e as estações existentes nos tributários encontrados entre estas duas estações. Os períodos considerados foram seca (outubro/novembro de 1983), cheia (junho/julho de 1983), subida das águas (fevereiro/março de 1984) e descida das águas (agosto/setembro de 1982).

$$
\left(\mathrm{Q}_{1} * \mathrm{C}_{1}\right)+\left(\mathrm{Q}_{2} * \mathrm{C}_{2}\right)+\ldots+\left(\mathrm{Q}_{\mathrm{n}} * \mathrm{C}_{\mathrm{n}}\right)+=\mathrm{Q} * \mathrm{C}
$$

onde:

$Q_{1}$ é a vazão na estação Vargem Grande;

$\mathrm{C}_{1}$ é a concentração de oxigênio dissolvido na estação Vargem Grande;

$Q_{2 \ldots . . n}$ é a vazão nas estações dos tributários;

$\mathrm{C}_{2 \ldots . \mathrm{n}}$ é a concentração de oxigênio dissolvido nas estações dos tributários;

Q é a vazão na estação de Óbidos, a qual foi obtida pela soma das vazões de entrada;

C é a concentração de oxigênio dissolvido na estação de Óbidos.

A diferença entre a entrada e saída do balanço (E) é desprezível se for menor que $10 \%$ e foi determinada de acordo com a seguinte equação:

$$
\mathrm{E}=\frac{\left|\sum_{\mathrm{n}=1}^{8}\left(\mathrm{Q}_{\mathrm{n}} * \mathrm{C}_{\mathrm{n}}\right)-(\mathrm{Q} * \mathrm{C})\right|}{\mathrm{Q} * \mathrm{C}} * 100
$$

Como os dados não apresentaram uma distribuição normal, foram utilizados testes não paramétricos. Quando mais de dois pontos de coleta foram comparadas, foi realizado o teste KruskalWallis ANOVA para verificar se em algum dos pontos houve diferença estatística significativa. $\mathrm{O}$ nível de significância utilizado foi de $5 \%$.

\section{RESULTADOS E DISCUSSÃO}

Em termos comparativos, a população da bacia do rio Piracicaba, densidade populacional igual a aproximadamente $238 \mathrm{hab} \mathrm{km}^{-2}$ (CBH-PCJ, 2000), produz um volume de esgoto expressivamente maior que a bacia do rio Amazonas, com aproximadamente 1 hab km² (ANA, 2002). O esgoto lançado nos cursos d'água sem tratamento prévio afeta profundamente os processos biogeoquímicos que ocorrem nos rios (Ballester et al.,1999). Em muitos casos, a vazão dos rios não é suficiente para promover a depuração de toda matéria orgânica e muitos processos vitais são afetados com o aumento da demanda por oxigênio. Neste sentido, no Estado de São Paulo, o parâmetro OD é um indicativo da qualidade da água de rios. Na bacia do rio Piracicaba a concentração do OD diminui consideravelmente entre Morungaba, no rio Jaguari e no ponto de coleta Copersucar, situado no rio Piracicaba (Figura 3), evidenciando o efeito do esgoto in natura na concentração de oxigênio dissolvido.

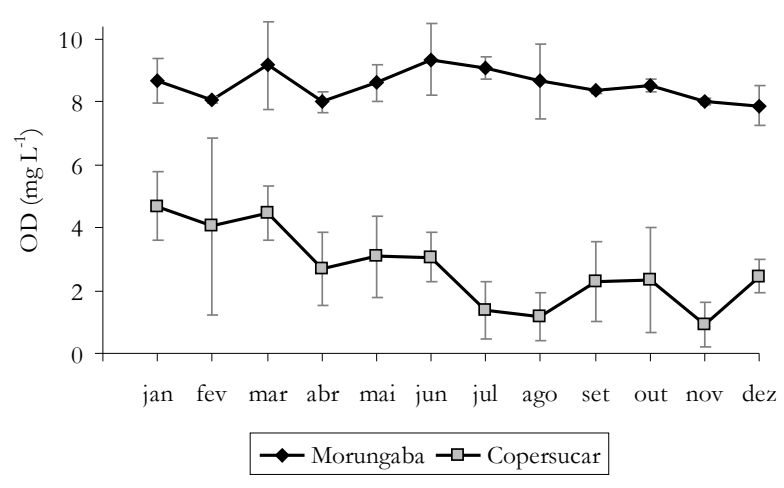

Figura 3 - Variação sazonal da concentração do oxigênio dissolvido nos pontos Morungaba (no rio Jaguari) e Copersucar (no rio Piracicaba). As barras verticais indicam o desvio padrão associado às médias.

Alguns trabalhos têm demonstrado que atividades agrícolas intensivas são fontes difusas de poluição, enquanto os grandes centros urbanos são fontes pontuais e o principal fator determinante da queda acentuada da concentração de OD nos cursos d'água (Toledo, 2001, Ometto et al., 2000). Portanto, observa-se que os baixos valores de oxigênio dissolvido encontrados ao longo do rio Piracicaba são determinados principalmente pelo grande volume de efluente lançado. 
No estado de Goiás, Silveira (2003) também observou essa influência no rio Paranaíba, onde valores elevados $\left(10 \mathrm{mg} \mathrm{L}^{-1}\right)$ de OD foram encontrados em pontos distantes de grandes fontes de poluição e valores baixos $\left(3,7 \mathrm{mg} \mathrm{L}^{-1}\right)$ de OD em um ponto localizado após a cidade de Goiânia, o qual recebe $95 \%$ do esgoto da cidade. Similarmente, Almeida \& Schwarzbold (2003) analisando a qualidade das águas do arroio da Cria Montenegro, no Rio Grande do Sul, encontraram valores baixos de OD (aproximadamente $2,5 \mathrm{mg} \mathrm{L}^{-1}$ ) no ponto final do curso d'água, o qual recebe variadas cargas poluentes, em relação a um ponto à montante deste que recebe menor carga poluente.

Na bacia Amazônica observam-se baixos valores de OD nos cursos d'água, com significativas variações sazonais conforme demonstrado na Figura 4. Os teores de oxigênio dissolvido foram menores no período da cheia, que ocorre entre os meses de junho e julho, atingindo valores de 3,6 a 4,0 $\mathrm{mg} \mathrm{L}^{-1}$, aumentando no período de seca, entre outubro e novembro, atingindo valores de aproximadamente $5,6 \mathrm{mg} \mathrm{L}^{-1}$. Uma correlação linear inversa significativa foi encontrada entre os teores de OD e a vazão medida na Marchantaria $\left(r^{2}=0,85 ; p=0,00002\right)$.

Valores semelhantes de OD foram encontrados por Saraiva et al. (2003) no rio Amazonas, variando de 4 a $5,4 \mathrm{mg} \mathrm{L}^{-1}$ na época da subida das águas.

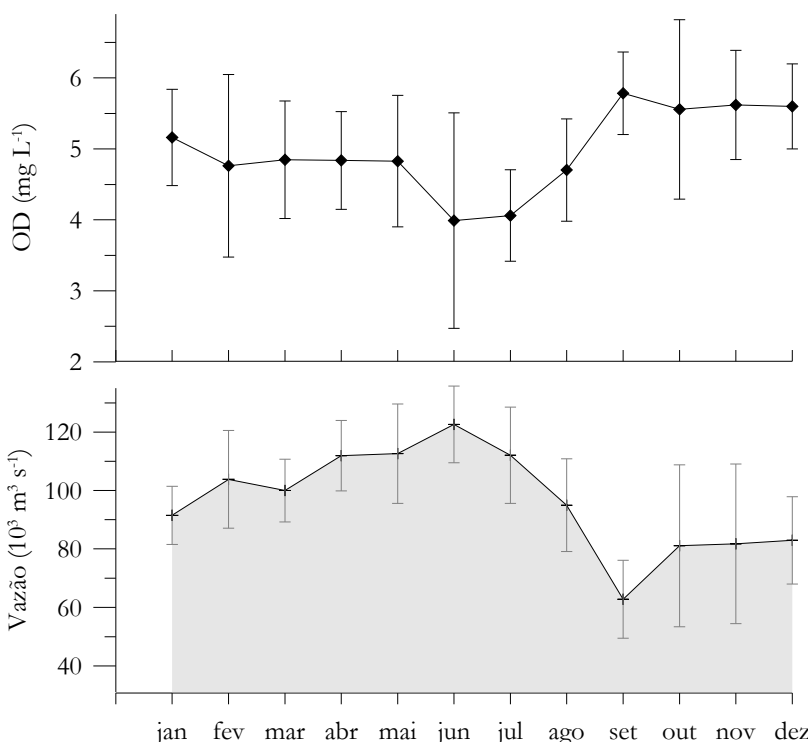

Figura 4 - Variação sazonal da concentração do oxigênio dissolvido em relação à vazão do rio Solimões no ponto Marchantaria. As barras verticais indicam o desvio padrão associado às médias.
Analisando-se as características das bacias Amazônica e do rio Piracicaba, observa-se que as diferenças são consideráveis, principalmente com relação à densidade populacional e a vazão dos rios. A bacia Amazônica dispõe de 740,75 $\mathrm{m}^{3} \mathrm{hab}^{-1} \mathrm{dia}^{-1} \mathrm{e}$ a bacia do rio Piracicaba de $1,61 \mathrm{~m}^{3} \mathrm{hab}^{-1} \mathrm{dia}^{-1}$. Assim um cenário intrigante é apresentado, duas regiões com características distintas quanto à densidade populacional e volume de efluentes lançados nos corpos d'água, mas que apresentam baixas concentrações de OD, em alguns pontos dos rios menores que $5 \mathrm{mg} \mathrm{\textrm {L } ^ { - 1 }}$, não atendendo aos padrões estabelecidos para as classes 1 e 2 da Resolução CONAMA $357 / 05$.

Vale lembrar que de acordo com a Resolução CONAMA 357/05, a concentração de OD na água deve estar dentro dos padrões estabelecidos de acordo com a sua utilização. A classificação varia de $1 \mathrm{a} 4$, sendo a classe 1 de melhor qualidade da água e a classe 4 de pior qualidade com relação a diversos parâmetros. Dentre esses, a concentração de OD referente às classes 1, 23 e 4 não deve ser inferior a $6,5,4$ e $2 \mathrm{mg} \mathrm{L}^{-1}$, respectivamente (CONAMA, 2005).

Comprovadamente, as baixas concentrações de $\mathrm{OD}$ e conseqüentemente a queda na qualidade da água do rio Piracicaba e seus tributários são determinados principalmente pelo grande volume de efluentes domésticos e industriais lançados nos corpos d'água. Em contrapartida, na região Amazônica essa afirmação não é válida tendo em vista a baixa densidade populacional, o baixo volume de esgoto gerado, a ausência de práticas agrícolas com uso e manejo intensivo do solo e a grande vazão do rio Solimões/Amazonas e de seus tributários.

Cálculos efetuados com dados de população e vazão das duas regiões analisadas demonstram que na bacia do rio Piracicaba para cada $1 \mathrm{~m}^{3}$ de esgoto gerado não-tratado tem-se $13,50 \mathrm{~m}^{3}$ de água fluvial disponível, enquanto na bacia Amazônica esta relação é de $1 \mathrm{~m}^{3}$ de esgoto para 40.501,26 $\mathrm{m}^{3}$ de água (Eq. 1 e 2). Neste contexto, considerando-se uma projeção em que houvesse na bacia Amazônica uma relação de esgoto gerado não-tratado e água disponível tal qual apresentado no cenário da bacia do rio Piracicaba, a população atendida com coleta de esgoto deveria ser de aproximadamente de 2,36 bilhões de habitantes.

Diante deste cenário uma questão vem à tona. Quais os fatores que podem estar determinando as baixas concentrações de OD no rio Solimões/Amazonas?

Observa-se que a bacia Amazônica apresenta baixas concentrações de OD em comparação à por- 
ção inicial da bacia do Piracicaba (ponto Morungaba) (Figuras 3 e 4). Tal fato é condicionado por processos inerentes às características da bacia e não pela ação antrópica. Na bacia do rio Amazonas a alta carga de sólidos em suspensão impede a penetração da luz inibindo a fotossíntese e, conseqüentemente, a produção de $\mathrm{O}_{2}$ (Devol et al., 1983; Hedges et al., 1986; Richey et al., 1986). Outro fator característico desta região é o arraste da matéria orgânica oriundo das várzeas, o qual aumenta no período de descida das águas quando a fração proveniente dos lagos de várzea é maior (Hedges et al., 1986; Richey et al, 1988). Assim, devido o consumo de $\mathrm{O}_{2}$ para a oxidação da matéria orgânica, o OD no rio Amazonas é relativamente baixo, ou seja, não saturado mesmo em regiões preservadas, quando comparado com os valores dos pontos mais preservados da bacia do rio Piracicaba.

Segundo Devol et al. (1995), a concentração do oxigênio dissolvido apresenta um ciclo sazonal que resulta principalmente das variações devido à diferença de profundidade do rio. Os extremos das curvas da concentração de oxigênio e da hidrógrafa no ponto Marchantaria ocorrem nos mesmos períodos, porém apresentam uma correlação inversa (Figura 4).

Estes autores têm proposto que o rio Amazonas está aparentemente em estado estacionário com relação ao oxigênio dissolvido e $\mathrm{CO}_{2}$ livre, ou seja, se a respiração for assumida como sendo a reação dominante envolvendo os dois gases, então em qualquer momento o consumo local de oxigênio pela respiração e conseqüente produção de $\mathrm{CO}_{2}$ livre é balanceado pela entrada e saída de $\mathrm{CO}_{2}$ através da interface ar-água. Então, quando a taxa respiratória volumétrica é integrada com a profundidade, a maior taxa aérea de respiração ocorre no período de águas altas e a menor taxa ocorre durante águas baixas. A troca do oxigênio é normalmente parametrizada como uma função do seu déficit de saturação na água. Desta forma, a queda na concentração de oxigênio ao ponto do déficit de saturação, ou seja, suficiente para balancear a nova taxa de respiração, seria um dos possíveis responsáveis pelo aumento da taxa local de respiração à medida que a profundidade da água aumenta. Isso pode resultar em um ciclo sazonal na concentração de $\mathrm{O}_{2}$ que é inversamente proporcional à profundidade do rio e a descarga, como é observado nos dados da série temporal de Marchantaria (Figura 4). Assim, o nível de OD nos rios da bacia Amazônica não é um bom indicador da qualidade da água quando utilizado isoladamente.

A menor concentração de oxigênio no rio Amazonas/Solimões ocorre na cheia, com uma con- centração de aproximadamente $4,0 \mathrm{mg} \mathrm{L}^{-1}$. Na seca (novembro), quando a concentração é máxima, alcança somente 6,6 $\mathrm{mg} \mathrm{L}^{-1}$ (Figura 5).

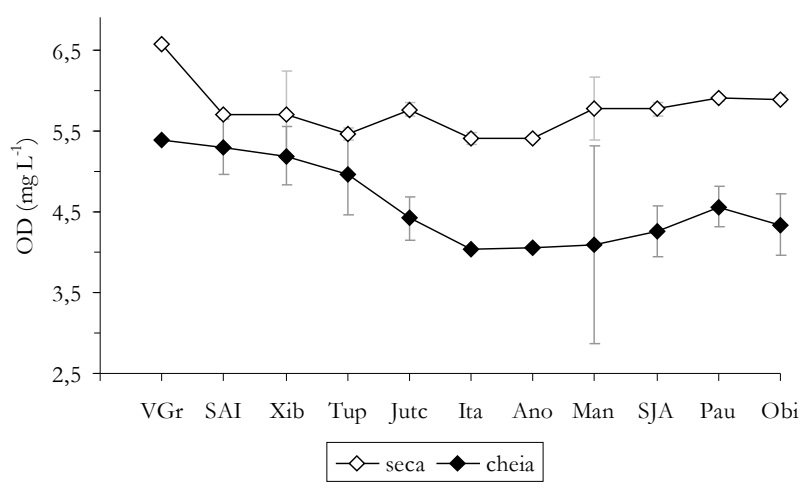

Estações: VGr - Vargem Grande; SAI - Santo Antônio do Içá; Xib Xibeco; Tup - Tupé; Jutc - Jutica; Ita - Itapeua; Ano - Anori; Man Manacapuru; SJA - São José do Amatari; Pau - Paura; Obi - Óbidos.

Figura 5 - Variação da concentração do oxigênio dissolvido no rio Solimões/Amazonas, nos períodos cheia (jun/83 e jul/84) e seca (nov/82 e nov/87). As barras verticais indicam o desvio padrão associado às médias.

Considerando a Resolução CONAMA $357 / 05$, durante a cheia o valor médio da concentração de OD (4,6 $\left.\mathrm{mg} \mathrm{L}^{-1}\right)$ das águas do rio Solimões/Amazonas não atende aos limites estabelecidos para as classes 1 e 2. Assim, estas não poderiam ser utilizadas para a irrigação das hortaliças e plantas frutíferas, à atividade de pesca, ao abastecimento para consumo humano apenas com um tratamento simplificado, à proteção das comunidades aquáticas, à recreação de contato primário etc. Nota-se que o uso do OD como um parâmetro restritivo para a classificação das águas é inadequado. A Resolução CONAMA erroneamente estabelece para cada classe os mesmos limites de OD em todo território nacional. Embora em algumas regiões com alto índice de urbanização e muitas fontes de poluição os baixos teores de OD estejam relacionados à má qualidade da água, este parâmetro também pode ser influenciado por características regionais como acontece na Amazônia.

Na bacia do rio Piracicaba a concentração média de OD varia de 1,2 a 8,7 $\mathrm{mg} \mathrm{L}^{-1}$ conforme Figura 6. 


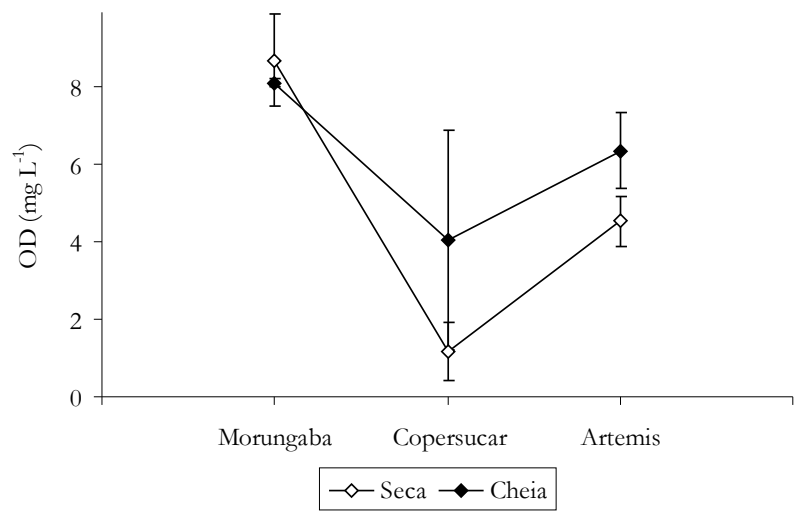

Figura 6 - Variação da concentração de OD na bacia do rio Piracicaba, nos períodos de cheia (fevereiro) e seca (agosto). As barras verticais indicam o desvio padrão associado às médias.

Na bacia do Piracicaba devido à entrada dos tributários, na região central da bacia, onde se concentram os maiores centros urbanos, a variação do OD é mais acentuada atingindo valores próximos de zero na estação Copersucar (Figura 3).

Os pontos Fazenda da Barra, Morungaba e Bairro da Ponte, localizados nos três rios formadores do rio Piracicaba, não apresentam diferença significativa com relação ao OD $(p=0,96)$. Assim o ponto Morungaba foi adotado como o ponto representativo da porção inicial da bacia. Ao comparar este com os demais pontos (Copersucar e Artemis), pôde-se constatar que existe diferença significativa $(p=0,001)$ entre eles. De acordo com a Figura 6 observa-se que na região das cabeceiras (ponto Morungaba), no período da cheia o OD é menor em relação ao período seca. Essa variação sazonal ocorre em função da diminuição da coluna d'água e sedimentação das partículas de sólidos suspensos que proporcionam maior penetração de luz e, conseqüentemente, maior taxa fotossintética. Nos pontos Copersucar e Artemis uma tendência inversa é observada, sendo os valores de OD maiores durante o período de cheia. Isto ocorre devido o aumento da vazão que por sua vez promove a diluição do esgoto que é jogado no rio.

Com relação ao comportamento do OD ao longo do canal principal do rio Solimões/Amazonas, com base no balanço de massa (Eq. 3 e 4), constatou-se que este é conservativo, não havendo outras entradas ou saídas significativas de OD no trecho entre Vargem Grande e Óbidos. Na bacia do rio Piracicaba, Ballester et al. (1999) fazendo um balanço de massa similar para o $\mathrm{OD}$ e $\mathrm{CO}_{2}$, observaram que estes, diferentemente da bacia Amazônica, não apresentam comportamento conservativo.

Tal como ocorre no canal principal, a concentração de OD nos tributários do rio Solimões/Amazonas é menor na cheia e maior na seca (Figura 7). Aparentemente, os tributários do rio Solimões/Amazonas parecem funcionar de maneira similar aos tributários localizados nas áreas mais preservadas do rio Piracicaba, os quais apresentam maiores teores de OD no período de seca como resultado do aumento da fotossíntese.

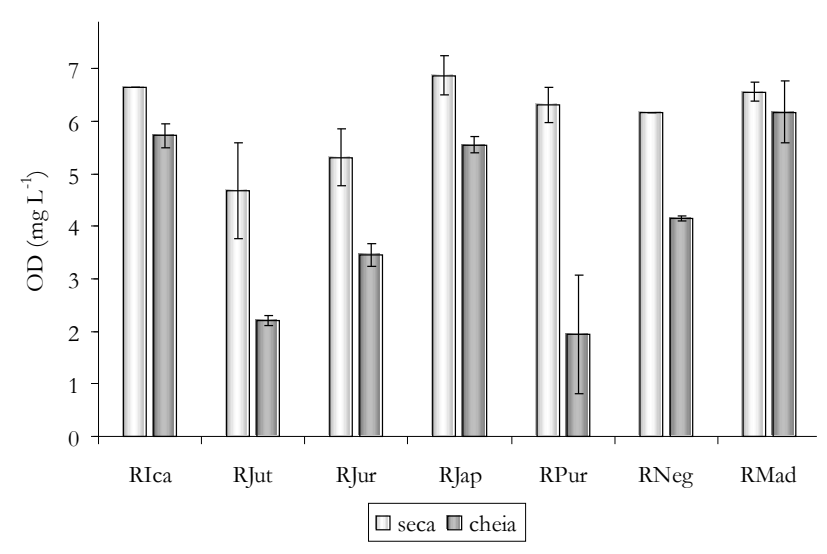

Estações: Rica - rio Içá; RJut - rio Jutaí; RJur - rio Juruá; RJap - rio Japurá; Rpur - rio Purus; RNeg - rio Negro; RMad - rio Madeira.

Figura 7 - Variação da concentração do oxigênio dissolvido nos tributários do rio Solimões/Amazonas nos períodos cheia (jun/83 e jul/84) e seca (nov/82 e nov/87). As barras verticais indicam o desvio padrão associado às médias.

Na bacia do rio Piracicaba, os níveis de OD nos tributários são críticos, devido ao baixo volume de água destes para diluição do esgoto doméstico, atingindo valores próximos de zero nos períodos de baixa precipitação, com exceção no ribeirão TijucoPreto, o qual drena uma área agrícola e o distrito de Tupi onde a população é pequena (Figura 8). Os ribeirões que apresentam situação mais crítica são aqueles que recebem os esgotos da cidade de Piracicaba e municípios adjacentes, como os ribeirões Enxofre e Tatu.

O ribeirão Piracicamirim até 1997 apresentava baixas concentrações de OD. No entanto, após a implantação do sistema de tratamento de esgoto esse ribeirão passou a apresentar valores de OD acima de $6 \mathrm{mg} \mathrm{L}^{-1}$ (Daniel et al., 2002). 


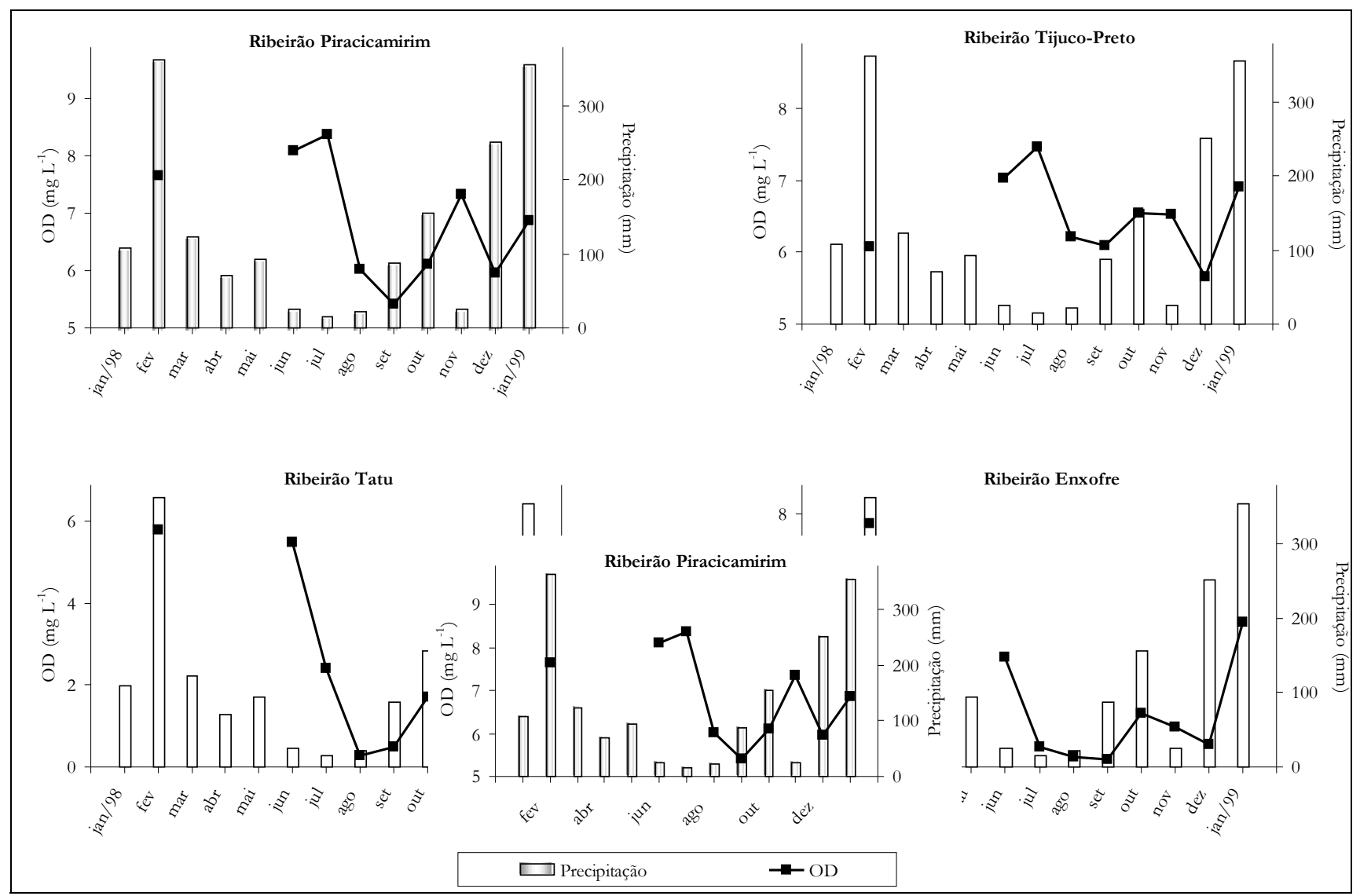

Figura 8 - Variação da concentração de oxigênio dissolvido nos tributários do rio Piracicaba ao longo do ano e da precipitação de jan/98 a jan/99.

\section{CONCLUSÕES}

No Brasil, a avaliação da qualidade da água é realizada a partir de critérios estabelecidos pela resolução CONAMA 357/05, a qual apesar de considerar diversos parâmetros, tem como um dos requisitos valores de OD, para águas destinadas aos usos mais nobres, de no mínimo 6,0 e $5,0 \mathrm{mg} \mathrm{L}^{-1}$ para as classes 1 e 2, respectivamente. Neste contexto, as águas do rio Amazonas seriam classificadas, por exemplo, como impróprias à proteção das comunidades aquáticas, o que é uma total incoerência já que a Amazônia abriga em seus rios e lagos uma grande diversidade de seres vivos.

Em regiões onde grande quantidade de efluentes domésticos e industriais é despejada diretamente nos rios, como por exemplo, na bacia do rio Piracicaba, podemos encontrar uma relação direta entre baixos teores de OD e má qualidade de água. No entanto, valores baixos de OD também podem resultar de processos naturais, como ocorre na bacia Amazônica. Desta forma, a avaliação da qualidade da água deve considerar outros fatores que causam diminuição no teor de oxigênio dissolvido, já que a concentração deste elemento varia em função de características físicas e climáticas regionais e não somente devido à interferência antrópica.

$O$ fato desta resolução não considerar a influência de características regionais nos valores de OD impossibilita sua aplicação em lugares onde valores relativamente baixos deste elemento não estão diretamente relacionados à interferência antrópica, não sendo portanto, decorrentes do lançamento de efluentes nos corpos d'água ou de uma outra fonte de poluição. 


\section{AGRADECIMENTOS}

Agradecemos aos Projetos CAMREX e PiraCena pela disponibilização dos dados, à Fundação de Amparo à Pesquisa do Estado de São Paulo e ao Centro de Energia Nuclear na Agricultura pelo apoio. Aos pesquisadores do CENA e aos revisores pelos comentários e sugestões sobre os manuscritos que deram origem a este artigo.

\section{REFERÊNCIAS}

ALMEIDA, M.A.B.; SCHWARZBOLD, A.. (2003). Avaliação sazonal da qualidade das águas do arroio da Cria Montenegro, RS com aplicação de um índice de qualidade de água (IQA). Revista Brasileira de Recursos Hídricos. v.8, nº p.81-97.

ANA - AGÊNCIA NACIONAL DAS ÁGUAS (2002). Regiões hidrográficas. Disponivel em: http://www.ana.gov.br/ mapainicial/doc_Mapal

5PanoramaporRH4_04_03.pdf. Acesso em: 07 ago. 2003.

BALLESTER, M.V.; MARTINELLI, L.A.; KRUSCHE, A.V.; VICTORIA, R.L.; BERNARDES, M.; CAMARGO, P.B. (1999). Effects of increasing organic matter loading on the dissolved $\mathrm{O}_{2}$, free dissolved $\mathrm{CO}_{2}$ and respiration rates in the Piracicaba river basin, southeast Brazil. Water Research. v.33, no9, p.2119-2129.

CBH-PCJ - COMITÊ DAS BACIAS HIDROGRÁFICAS DOS RIOS PIRACICABA, CAPIVARI E JUNDIAÍ (2000). Relatório Zero. Disponivel em: http://www.comitepcj .sp.gov.br. Acesso em: 07 ago. 2003.

CONSELHO NACIONAL DO MEIO AMBIENTE - CONAMA (2005). Resolução n 357, de 17 de março de 2005. Disponivel em: http://www.mma.gov.br/port/ conama/index.cfm. Acesso em: 17 mar. 2005.

DANIEL, M.H.B.; MONTEBELO, A.A., BERNARDES, M.C., OMETTO, J.P.; CAMARGO, P.B.; KRUSCHE, A.V.; BALLESTER, M.V.; VICTORIA, R.L.; MARTINELLI, L.A. (2002). Effects of urban sewage on dissolved oxygen, dissolved inorganic and organic carbon, and electrical conductivity of small streams along a gradient of urbanization in the Piracicaba river basin. Water, Air, and Soil Pollution, v.136, p.189-206.

DEVOL, A.H.; DOS SANTOS, A.; FORSBERG, B.R.; ZARET, T.M. (1983). Nutrient addition experiments in Lago Jacaretinga, Central Amazon, Brazil. 2. The effect of humic and fulvic acids. Hydrobiologia, v.109, p.97103.
DEVOL, A.H.; FORSBERG, B.R.; RICHEY, J.E.; PIMENTEL, T.P. (1995). Seasonal variation in chemical distributions in the Amazon (Solimões) River: a multiyear times series. Global Biogeochemical Cycles, v.9, n³, p.307-328.

ESALQ - ESCOLA SUPERIOR DE AGRICULTURA "LUIZ DE QUEIROZ" (2003). Dados de precipitação: posto agrometeorológico. Departamento de Ciências Exatas. Disponível em: http://ce.esalq.usp.br/dce/ posto.htm. Acesso em: 04 set. 2003.

FORSBERG, B.R.; DEVOL, A.H.; RICHEY, J.E.; MARTINELLI, L.A.; DOS SANTOS, H. (1988). Factors controlling nutrient concentrations in Amazon floodplain lakes. Limnology and Oceanography, v.33, nº p.41-56.

HEDGES, J.I.; CLARK, W.A.; QUAY, P.D.; RICHEY, J.E.; DEVOL, A.H.; SANTOS, U.M. (1986). Compositions and fluxes of particulate organic material in the Amazon River. Limnology and Oceanography, v.31, n4, p.717-738.

KRUSCHE, A.V.; CARVALHO, F.P.; MORAES, J.M.; CAMARGO, P.B.; BALLESTER, M.V.R.; HORNINK, S.; MARTINELLI, L.A.; VICTORIA, R.L. (1997). Spatial and temporal water quality variability in the Piracicaba river basin, Brazil. Journal of the American Water Resources Association, v. 33, n5, p.1117-1123.

MARTINELLI, L.A.; KRUSCHE, A.V.; VICTORIA, R.L.; CAMARGO, P.B.; BERNARDES, M.; FERRAZ, E.S.; MORAES, J.M.; BALLESTER, M.V.R. (1999). Effects of Sewage on the Chemical Composition of Piracicaba River, Brazil. Water, Air, and Soil Pollution, v. 110, p.67-79.

MARTINELLI, L.A.; SILVA, A.M.; CAMARGO, P.B.; MORETTI, L.R.; TOMAZELLI, A.C.; SILVA, D.M.L.; FISCHER, E.G.; SONODA, K.C.; SALOMÃO, M.S.M.B. (2002). Levantamento das cargas orgânicas lançadas nos rios do estado de São Paulo. Biota Neotropica, v.2, n². Disponivel em: http://www.biotaneotropica.org. br/v2n2/pt/item?article. Acesso em: ago. 2003.

MOURA, J.M.S. (2005). Variação na composição isotópica do metano $\left(\mathrm{CH}_{4}\right)$ em sedimentos de igarapés na Amazônia oriental. Piracicaba, 83 p. Dissertação (mestrado) - Escola Superior de Agricultura "Luiz de Queiroz", Universidade de São Paulo.

OMETTO, J.P.H.B.; MARTINELLI, L.A.; BALLESTER M.V.; GESSNER, A.; KRUSHE, A.V.; VICTORIA, R.L.; WILLIANS, M. (2000). Effects of land use on water chemistry and macroinvertebrates population in two streams of Piracicaba River Basin, Southeast Brazil. Freshwater Biology, v.44, n², p.327-338.

RICHEY, J.E.; MEADE, R.H.; SALATI, E.; DEVOL, A.H.; NORDIN, C.F.Jr.; SANTOS, U.M. (1986). Water discharge and suspended sediment concentrations in the Amazon River: 1982-1984. Water Resources Research, v.22, n5, p.756-764. 
RICHEY, J.E.; DEVOL, A.H.; WOFSY, S.C.; VICTORIA, R.L.; RIBERIO, M.N.G. (1988). Biogenic gases and the oxidation and reduction of carbon in Amazon River and floodplain waters. Limnology and Oceanography, v.33, $n^{\circ} 4$, p. $551-561$.

RICHEY, J.E.; HEDGES, J.I.; DEVOL, A.H.; QUAY, P.D.; VICTORIA, R.L.; MARTINELLI, L.A.; FORSBERG, B.R. (1990). Biogeochemistry of carbon in the Amazon River. Limnology and Oceanography, v.35, $\mathrm{n}^{\circ} 2$, p.352-371.

SARAIVA, A.L.L.; DELFINO, I.B.; SANTOS, M.L.S.; BORDALO, A.O. (2003). Distribuição de material em suspensão no rio Amazonas. (compact disc). In: CONGRESSO BRASILEIRO DE LIMNOLOGIA, 9., Juiz de Fora, 2003. Água - rompendo fronteiras entre ciência, educação e cidadania. Resumos. Juiz de Fora: UFJF/ICB.

SILVEIRA, A.V.T.; SILVA, L.C.F.; OLIVEIRA, L.G. (2003). Caracterização físico-química dos recursos hídricos da bacia do Paranaíba, estado de Goiás (compact disc). In: CONGRESSO BRASILEIRO DE LIMNOLOGIA, 9., Juiz de Fora, 2003. Água - rompendo fronteiras entre ciência, educação e cidadania. $R e-$ sumos. Juiz de Fora: UFJF/ICB.

TELLES, E.C.C. (2002). Dinâmica do carbono no solo influenciada pela textura, drenagem, mineralogia e carvões em florestas primárias na região centro-oriental da Amazônia. Piracicaba, 114 p. Tese (doutorado) Centro de Energia Nuclear na Agricultura, Universidade de São Paulo.

TOLEDO, A.M.A. (2001). Evolução espaço-temporal da estrutura da paisagem e sua influência na composição química das águas superficiais dos ribeirões Piracicamirim e Cabras (SP). Piracicaba, 94 p. Dissertação (mestrado) - Centro de Energia Nuclear na Agricultura, Universidade de São Paulo.

WETZEL, R.G. (1975). Limnology. Philadelphia: W. B. Saunders Company, $743 p$.

\section{The State of Dissolved Oxygen in Brazilian Waters}

\section{ABSTRACT}

Understanding the behavior of Dissolved Oxygen (DO) in watercourses is essential to identify the possible agents which cause environmental disequilibrium. In some regions of Brazil dramatic variations of DO concentration have been observed in rivers with different disturbance levels. This study analyzed the status of dissolved oxygen in the hydrographic basins of the Amazon River and the Piracicaba River located in the north and southeast of Brazil, respectively, identifying the agents or processes responsible for the DO level variations in those systems. In for the DO level variations in those systems. In Piracicaba River, low dissolved oxygen concentrations were observed, related to point sources of pollution from anthropogenic activities, (e.g. large quantities of untreated sewage discharged into the rivers). The dissolved oxygen concentration declines downstream showing mean values that vary from $8.7 \mathrm{mg} \mathrm{L}^{-1}$ in the headwaters to $1.2 \mathrm{mg} L^{-1}$ downstream of large cities. This trend indicates that domestic and industrial sewage reduces water quality. Low values were also observed in the Amazon River. Nevertheless, these variations stem from natural processes, mainly due to oxidation of organic matter and the seasonality in the hydrological cycle leading to values which varied from 4.0 $m g L^{-1}$ to $5.4 \mathrm{mg} \mathrm{L}^{-1}$ during the high water period (June July) to $6.6 \mathrm{mg} \mathrm{L}^{-1}$ during the low water period (November). We conclude that in Brazil, water quality assessments should consider other factors which could reduce the dissolved oxygen content since its concentration varies not only due to human interference but also to regional climate and physical characteristics.

Key-words: dissolved oxygen; Amazon River, Piracicaba River, water quality, sewage. 